Category: Teaching \& Learning at times of uncertainty

\title{
Type of e-resources for asynchronous online learning in pre-clinical year 2 during the COVID-19 pandemic
}

\author{
Alwani, S.F. \& Shukri, A.M. \\ Universiti Teknologi MARA, Malaysia
}

\section{Background:}

The COVID-19 pandemic has taken many countries by storm and forces many higher institutions to embark from a face-to-face learning to a complete online distance learning method. This is due to the need to close all tertiary education centres for pre-clinical basic sciences teaching as one of the measures to reduce the spread of the disease. In Faculty of Medicine UiTM, our institution has already been equipped with our own platform for delivering learning content online and the academicians were quick to adapt and utilize the platform. The aim of the study is to describe the type of resources used for Online Learning by academicians in the Faculty of Medicine UiTM.

\section{Method:}

Data was collected at the start of Movement Control Order (MCO) from April 2020 to January 2021 to look at the type of e-Resources uploaded in the UiTM online platform (uFuture) by academicians across all disciplines in Year 2 teaching modules. The type of e-resources were power point slides, infographic, and videos of recorded presentation supported by $\mathrm{mp} 4$, Ms Stream, a weblink connected to YouTube channel, and Google Drive.

\section{Results:}

Out of a total of 6 modules, the Gastrointestinal Module (GITM) had the least of video recording (45\% of total digital learning material) and the Central Nervous System Module (CNSM) had the most digital learning material uploaded in a form of recorded video presentation which is $85 \%$. The GITM occurred just before at the start of MCO and the CNSM had just recently over.

\section{Conclusion:}

There is a migration towards video recorded from power point presentation in the type of e-resources being delivered to the students. This could be due to exposure and new skills developed by our lecturers throughout the pandemic.

Keywords: E-resource, asynchronous learning, online platform 